УДК 616.89-008.441.44:616.053.7:616.89.008.444.9:343.225-3-055.52

Для цитирования: Меринов А.В., Байкова М.А. Влияние воспитания в семьях, имеющих родителя, страдающего алкогольной зависимостью, на аутоагрессивную траекторию потомства. Сибирский вестник психиатрии и наркологии. 2018; 4 (101): 87-92. https://doi.org/10.26617/1810-3111-2018-4(101)-87-92

\title{
Влияние воспитания в семьях, имеющих родителя, страдающего алкогольной зависимостью, на аутоагрессивную траекторию потомства
}

\section{Меринов А.В., Байкова М.А.}

Рязанский государственный медицинский университет им. акад. И.П. Павлова

390010, Рязань, ул. Высоковольтная, д. 9

\section{PEЗЮME}

Проблема взрослых детей алкоголиков начала подниматься различными психиатрическими и наркологическими службами около 10 лет назад. Несмотря на отчетливый тренд на снижение заболеваемости алкогольной зависимостью, процент лиц, воспитанных в алкогольных семьях, остается высоким. Известно, что воспитание в подобной семье влечет за собой целый пласт различного рода психологических и социальных проблем, которые порой оказываются скрытыми от постороннего глаза. Цель: исследовать аутоагрессивные характеристики девушек и юношей, выросших в алкогольных семьях. Материалы и методы исследования. В исследовании приняли участие 90 незамужних девушек и 100 неженатых юношей, воспитанных в семьях, где хотя бы один из родителей страдал алкогольной зависимостью (основная группа), Контрольную группу составили 200 девушек и 180 юношей, не имеющих родителя, страдающего алкогольной зависимостью. Статистическая обработка проводилась посредством параметрических и непараметрических методов математической статистики. Результаты исследования. В основной группе обнаружено достоверно большее количество паттернов как классического, так и неклассического суицидального поведения. Юноши основной группы в $12 \%$ случаев имеют в анамнезе суицидальную попытку, в то время как в контрольной группе этот процент равен 0. Девушки основной группы почти в 5 раз чаще, чем респондентки контрольной группы, пытались совершить суицид. Дети, воспитывающиеся в семьях, где родитель имеет алкогольную зависимость, составляют особую группу с повышенным риском суицидальной активности. Выводы. Полученные данные расширяют существующие представления о негативном влиянии воспитания в алкогольной семье, убедительно демонстрируют тот факт, что алкогольная зависимость родителей является важным просуицидальным феноменом, а также указывают на необходимость создания в системе понимания врачей специалистов кризисных, а также превентивных служб дефиниции Взрослых Детей Алкоголиков.

\section{Ключевые слова: взрослые дети алкоголиков, аутоагрессивное поведение, суицидология, алкоголизм.}

\section{ВВЕДЕНИЕ}

Взрослые дети алкоголиков (ВДА) вследствие комплекса испытываемых ими негативных последствий взросления в алкогольной семье стали подвергаться пристальному вниманию исследователей относительно недавно. Основной пик научного интереса к данной тематике пришелся на прошлое десятилетие как в нашей стране, так и за рубежом [1, $2,3,4,5,6]$, когда было предпринято широкое изучение феномена созависимости. Многоаспектное исследование созависимости чаще выполнялось на когорте жен и матерей лиц, страдающих алкогольной зависимостью, в то время как изучение детей, выросших в алкогольной семье, осуществлялось не так активно, так как зачастую представляло собой лишь констатацию негативных последствий воспитания, повышенной аутоагрессивности, склонности к аддиктивному поведению, низкой самооценки и рассматривалось с позиции вовлеченности в перспективу созависимости. В момент массового появления исследований о ВДА постулировалась ключевая идея о том, что люди, выросшие в семьях с актуальной алкогольной историей, на протяжении жизни реализуют тот негативный психологический опыт, который был получен ими в детстве $[1,6,7,8,9,10]$. Актуальность проблемы ВДА обусловлена не столько их социальной дезадаптацией и виктимностью, сколько значительной распространенностью ВДА как явления [5].
Так, в США около 40-60 \% взрослых людей имеют в роду больных алкоголизмом, аналогичные данные приводятся в исследования южно-корейских учёных [5, 11]. Экстраполируя приведенные общемировые данные на Российскую Федерацию, даже с учетом текущего тренда на снижение уровня заболеваемости алкогольной зависимостью, можно с уверенностью говорить, учитывая длительную «алкогольную карьеру» нашей страны, о том, что число ВДА варьирует приблизительно от 15 до $50 \%$ населения [1]. При этом исследователи в своих работах отмечают, что по мере увеличения среднего возраста популяционного среза доля ВДА в нем уменьшается в связи с их меньшей продолжительностью жизни [3, 4].

В литературе встречаются работы, касающиеся суицидального поведения взрослых, выросших в семьях, где хотя бы один родитель страдал от алкогольной зависимости. Вектор работ касается преимушественно завершенных самоубийств [7, 8, 12]. Констатируется тот факт, что более трети покончивших с собой детей и подростков имели родителей, страдающих различными психическими расстройствами, в структуре которых встречалась и превалировала алкогольная зависимость, что указывает не только на высокую суицидальную напряженность, но и на высокий уровень стрессовых факторов, порождаемый родителем, страдающим алкогольной зависимостью [6]. 
В исследованиях, посвященных завершенным суицидам взрослых людей, значительное число погибших посмертно были отнесены к суицидентам, выросшим в семьях, где родитель страдал алкогольной зависимостью $[3,10]$. Данное положение так же согласуется с нашим предположением об уровне актуального стресса и негативном влиянии воспитания родителем алкоголиком.

Учитывая приведенные сведения, полученные в многочисленных исследованиях $[1,2,3,4,5,6,7,8$, $9,10,11,12]$, мы решили рассмотреть проблему ВДА с обратной стороны, то есть изучить представленность факторов, имеющих отношение к суицидальному поведению ВДА.

\section{ЦЕЛЬ ИССЛЕДОВАНИЯ}

Провести комплексный анализ факторов риска суицидальной активности девушек и юношей, выросших в алкогольных семьях.

\section{МАТЕРИАЛ И МЕТОДЫ}

Для решения поставленных задач были обследованы взрослые дети алкоголиков. В основную исследовательскую выборку вошли 90 незамужних девушек (ДА) (средний возраст которых составлял $20,5 \pm 1,5$ года) и 100 неженатых юношей (ЮА)

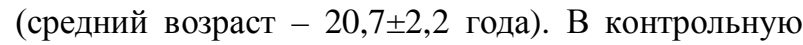
группу были включены 200 девушек (ДнА) (их

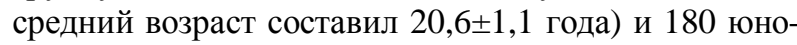
шей (ЮнА) (средний возраст - 21,2 1,7 года), не имеющих родителя, страдающего алкогольной зависимостью.

Критериями включения в основную (экспери- ментальную) группу являлись самостоятельная (анонимная) оценка хотя бы одного из своих родителей как страдающего алкогольной зависимостью, а также самостоятельное заполнение их родителями бланка теста CAGE. В случае совпадения обеих оценок, а также при наличии информированного согласия всех участников молодые люди относились к группе ВДА.

Критерием включения в контрольную группу являлось отсутствие указаний на наличие алкогольной болезни у одного из родителей. Все наблюдения, вызывающие сомнения по тем или иным причинам, из исследования исключались.

В качестве основного диагностического инструмента использовался опросник для выявления аутоагрессивных паттернов и их предикторов в прошлом и настоящем [2].

Статистический анализ и обработку данных проводили посредством параметрических и непараметрических методов математической статистики (с использованием критериев Стьюдента и Вилкоксона).

\section{РЕЗУЛЬТАТЫ И ИХ ОБСУЖДЕНИЕ.}

Суицидологические характеристики юночей, выросших в семьях, где родитель страдал алкоголизмом

Основные суицидологические характеристики юношей, выросших в семьях, где родитель страдал алкогольной зависимостью, достоверно отличающие их от юношей из семей, где родители не имели проблем с алкоголем, приведены в таблице 1.

Т а б ли ц а 1

Суицидологические характеристики юношей, имеющих и не имеющих страдающего алкоголизмом родителя (пары сравнений; $\mathbf{p}<0,05$ )

\begin{tabular}{|l|c|c|c|c|}
\hline \multicolumn{1}{|c|}{ Признак } & ЮА n (\%) & ЮнА n (\%) & $\chi^{2}$ & $\mathrm{p}$ \\
\hline Суицидальная попытка в анамнезе & $12(12)$ & $0(0)$ & 19,74 & 0,00001 \\
\hline Суицидальные мысли в анамнезе & $34(34)$ & $10(5,5)$ & 39,27 & 0,00001 \\
\hline Суицидальная попытка у родственника & $12(12)$ & $4(2,2)$ & 9,66 & 0,018 \\
\hline Моменты острого одиночества & $60(60)$ & $51(28,2)$ & 26,94 & 0,00001 \\
\hline Моменты безысходности & $48(48)$ & $40(22,2)$ & 19,84 & 0,00001 \\
\hline Склонность к перееданию, отказу от пищи & $34(34)$ & $30(16,6)$ & 10,95 & 0,0009 \\
\hline Отсутствие смысла жизни & $22(22)$ & $12(6,6)$ & 14,17 & 0,0002 \\
\hline Нанесение самоповреждений & $34(34)$ & $14(7,7)$ & 31,12 & 0,00001 \\
\hline Употребление наркотических веществ (несистематическое) & $34(34)$ & $28(15,5)$ & 12,69 & 0,0004 \\
\hline Склонность к неоправданному риску & $56(56)$ & $44(24,4)$ & 27,88 & 0,0000 \\
\hline Наличие термической патологии & $22(22)$ & $12(6,6)$ & 14,17 & 0,0002 \\
\hline
\end{tabular}

При оценке данных таблицы 1 не вызывает сомнений высокий уровень аутоагрессивности, как в своей классической ипостаси, так и в русле неклассической аутоагрессии, респондентов ЮА по сравнению с контрольной группой. Юноши ВДА достоверно чаще имеют суицидальную попытку и суицидальные мысли в анамнезе, что согласуется с данными, полученными другими исследователями $[3,5]$. Данный кластер демонстрирует повышенный уровень так называемой классической суицидальности респондентов ЮА. Помимо того, обращает на себя внимание высокий уровень респондентов основной группы, у которых близкий родственник пытался покончить жизнь суицидом (встречающийся почти в 6 раз чаще, чем в контрольной группе). Подобный факт семейной биографии респондентов указывает на семейную трансляцию суицидального поведения как приемлемую, описывающую жизненную траекторию и определенный стиль реагирования на разного рода неблагоприятные жизненные ситуации $[13,14,15]$. Такой тип ответа на воздействие стрессоров, если он встречался среди близких родственников, особенно родителей, закрепляется в качестве способа «решения» проблем и предполагает описанный в литературе «хамартический сценарий жизни» $[14,15]$. 
Данное предположение логично дополняет наличие у респондентов ЮА большого количества предикторов суицидального поведения, представленных гипотимическим эмоциональным спектром, включающим такие чувства как одиночество, безысходность, убежденность в отсутствии смысла и ценности жизни. Респонденты ЮА также характеризуются высоким уровнем представленности в своем аутоагрессивном диапазоне паттернов неклассической суицидальности по сравнению с контрольной группой: нанесение себе телесных самоповреждений, эпизоды приема психоактивных веществ, склонность к рискованному поведению. Резюмируя полученные данные, можно констатировать, что юноши ВДА характеризуются значительно большим количеством статистически значимых отличий как по суицидальным, так и по несуицидальным паттернам аутоагрессивного поведения и их предикторов. Полученные данные превышают таковые в контрольной группе в 2-4 раза, что позволяет рассмат- ривать основную исследовательскую выборку как весьма специфическую и неблагоприятную с позиций суицидологии.

Учитывая всё вышесказанное, мы можем утверждать, что наличие алкогольной зависимости у родителя в качестве значимого просуицидального феномена для детей мужского пола, безусловно, требует пристального внимания в превентивной диагностике суицидального поведения.

Перейдем к анализу выявленных суицидологических характеристик девушек, выросших в семьях, где хотя бы один родитель страдал алкогольной зависимостью.

Суицидологические характеристики девушек, выросших в семьях, где родитель страдал алкогольной зависимость.

Обнаруженные суицидологические особенности девушек, воспитанных в семьях, где родитель страдал алкогольной зависимостью, представлены в таблице 2.

Т а бли ц а 2

Суицидологические характеристики девушек, имеющих и не имеющих страдающего алкоголизмом родителя (пары сравнений; $\mathbf{p}<0,05$ )

\begin{tabular}{|l|c|c|c|c|}
\hline \multicolumn{1}{|c|}{ Признак } & ДА n (\%) & ДнА n (\%) & $\chi^{2}$ & $\mathrm{p}$ \\
\hline Суицидальная попытка в анамнезе & $15(16,7)$ & $7(3,5)$ & 13,53 & 0,0002 \\
\hline Суицидальные мысли в анамнезе & $30(33,3)$ & $28(14,0)$ & 14,5 & 0,0001 \\
\hline Моменты острого одиночества & $58(64,4)$ & $78(39,0)$ & 16,14 & 0,0001 \\
\hline Склонность к навязчивым угрызениям совести & $39(43,3)$ & $40(20,0)$ & 17,05 & 0,0000 \\
\hline Отсутствие смысла жизни & $9(10,0)$ & $9(4,5)$ & 2,35 & 0,1253 \\
\hline Обращение к психиатру, психотерапевту & $16(17,8)$ & $18(9,0)$ & 52,51 & 0,0000 \\
\hline Подверженность насилию & $13(14,4)$ & $7(3,5)$ & 9,94 & 0,0016 \\
\hline Наличие опасных для жизни хобби & $16(17,8)$ & $12(6,0)$ & 9,87 & 0,0017 \\
\hline Наличие черепно-мозговой травмы & $9(10,0)$ & $6(3,0)$ & 4,86 & 0,0276 \\
\hline Наличие термической патологии & $9(10,0)$ & $8(4,0)$ & 3,03 & 0,0815 \\
\hline
\end{tabular}

При анализе данных, приведенных в таблице 2, выявлено, что в группе девушек ВДА в отношении классических суицидальных паттернов поведения (суицидальные мысли и суицидальные попытки) прослеживается аналогичная тенденция, пррисущая юношам ВДА. При этом ситуация с паттернами поведения в русле неклассической аутоагрессии несколько отличается. Пул неклассической суицидальности представлен соматическим и самоповреждающим направлениями, как и в группе ЮА, повышенной уязвимостью вследствие личностной виктимности (опасные для жизни привычки и хобби, случаи физического и сексуального насилия в прошлом).

Девушек основной группы характеризует и высокая частота обнаружения предикторов суицидального поведения в рамках гипотимического спектра эмоционального реагирования: чувство одиночества и вины, склонность к угрызениям совести, раскаяние, самокритика, что логично дополняется опытом обращения к психиатру. В совокупности с вышеописанными признаками тревожность и низкая эмпатия расширяют общепринятую аутоагрессивную характеристику девушек ВДА и формирут безрадостный, полный отчаяния жизненный фон, опреде- ляют позицию жертвы как основополагающий и ролевой жизненный стереотип, предполагая ведущий сценарий страдания. Подобная «драматическая» позиция респонденток ДА, по данным различных авторов [14, 15], не предполагает под собой какой-либо счастливой судьбы, наполненной радостью жизни и видимым, отчетливым смыслом. Более того, основным жизненным кредо, как и в случае респондентов ЮА, является отсутствие либо скоротечность какого-либо успеха в жизни, что подтверждает экзистенцильную позицию «мученика», «страдальца» и определяет внутренние психологические выгоды, обусловленные семейным программированием» $[14,15]$.

Учитывая полученные данные, мы решили более детально рассмотреть соотнесение алкогольной зависимости родителя со спектром аутоагрессивной активности в отношении девушек ВДА. При этом обнаружена гетерогенность данной когорты в отношении разных феноменов аутоагрессии (низкая самооценка и самонеприятие, деструктивные установки) в зависимости от парентальной фигуры родителя, страдающего алкогольной зависимостью, а также от того, страдает алкогольной зависимостью один родитель или оба. 
В рамках «пилотного» входного исследования мы разделили группу всех девушек ВДА на три группы: 1) девушки ВДА, у которых только отец страдает алкогольной зависимостью; 2) девушки ВДА, у которых только мать страдает алкогольной зависимостью; 3) девушки ВДА, у которых оба родителя страдают алкогольной зависимостью. Кроме того, была выделена контрольная группа. При сравнении контрольной группы с вышеобозначенными группами в отношении признаков классической и неклассической аутоагрессивности, а также их предикторов обнаружено, что группа девушек ВДА, имеющих отца, страдающего алкоголизмом, практически не отличается от контрольной группы. В то время как две другие группы в отношении суицидальной направленности по отношению к контрольной группе расположились в порядке увеличения суицидогенности: контрольная группа $\rightarrow$ девушки ВДА, у которых мать страдает алкогольной зависимостью $\rightarrow$ девушки ВДА, у которых оба родителя страдают алкоголизмом. В наиболее аутоагрессивной группе выявлены высокие показатели как в отношении классических суицидальных факторов и предикторов, так и неклассических. В группе девушек ВДА, у которых только мать страдает алкогольной зависимостью, наиболее высокие показатели обнаружены в отношении несуицидальной аутоагрессии.

Полученные данные позволяют рассматривать взрослых девушек, выросших в семьях больных алкогольной зависимостью, как группу повышенного суицидального риска, соответственно факт наличия алкогольной зависимости у родителя следует отнести к важным просуицидальным факторам (предикторам) для детей женского пола.

\section{ЗАКЛЮЧЕНИЕ}

Рождение и воспитание в условиях семьи, где хотя бы один из родителей страдает алкогольной зависимостью, увеличивает активность аутоагрессивного радикала и антивитального стиля поведения у потомства. В связи с чем девушки и юноши, выросшие в алкогольных семьях, входят в группу потенциального повышенного суицидального риска. Полученные данные диктуют необходимость прояснения и уточнения семейного анамнеза (наличие психических расстройств, лечение у психиатра, депрессия, алкоголизм, суицидальные наклонности) и пристального внимания кризисных и превентивных служб в отношении взрослых детей алкоголиков.

Учитывая возрастающее количество и распространенность в общей популяции лиц, воспитанных в алкогольных семьях, становится понятной острая потребность в разработке и внедрении психокоррекционно-педагогических и психотерапевтических программ сопровождения детей, подростков и их семей, создании сообществ для помощи взрослым детям алкоголиков, формировании и обосновании понятия, подхода, дефиниции, определения социально-психологических механизмов такого предиспонирующего аутоагрессию фактора, как «послед- ствия рождения и воспитания в условиях семьи больного алкогольной зависимостью», в ознании врачей психиатров, психотерапевтов и ных специалистов, работающих в сфере профилактики суицидального поведения подростков.

КОНФЛИКТ ИНТЕРЕСОВ

Авторы декларируют отсутствие явных и потенциальных конфликтов интересов в связи с публикацией данной статьи.

\section{ИСТОЧНИК ФИНАНСИРОВАНИЯ}

Авторы заявляют об отсутствии финансирования при проведении данного исследования.

\section{СООТВЕТСТВИЕ ПРИНЦИПАМ ЭТИКИ}

Исследование аутоагрессивных характеристик девушек и юношей, выросших в алкогольных семьях, проведено с соблюдением норм современной биомедицинской этики и этических стандартов, разработанных в соответствии с Хельсинской декларацией ВMА.

\section{ЛИТЕРАТУРА}

1. Москаленко В.Д. Наркологические, психопатологические нарушения, психологические проблемы в популяции взрослых сыновей и дочерей больных зависимостями. Сибирский вестник психиатрии и наркологии. 2006; 3 (42): 55-61.

2. Balsa A.I., Homer J.F., French M.T. The health effects of parental problem drinking on adult children. J. Ment. Health Policy Econ. 2009; 2 (12): 55-66.

3. Hall C.W., Webster R.E. Traumatic symptomatology characteristics of adult children of alcoholics. J. Drug Educ. 2002; 3 (32): 195-211.

4. Giuta C.T., Compas B.E. Adult daughters of alcoholics: are they unique? J. Stud. Alcohol. 1994; 5 (55): 600-606.

5. Jordan S. The promotion of resilience and protective factors in children of alcoholics and drug addicts. Bundesgesundheitsblatt Gesundheitsforschung Gesundheitsschutz. 2010; 4 (53): 340346.

6. Woititz J.G. Guidelines for support groups; adult children of alcoholics and others who identify including guide to step 4 inventory. Health Communication. Inc. Pompano Beach, Florida, 1986: 37.

7. Van Den Berg N., Hennigan K., Hennigan D. Children of parents in drug/alcohol programs: are they underserved? Alcohol Treat. Quart.1989; 3 (4):1-25.

8. Шустов Д.И., Меринов А.В. Диагностика аутоагрессивного поведения при алкоголизме методом терапевтического интервью. Пособие для врачей психиатров-наркологов и психотерапевтов. М.: МЗ РФ, 2000: 20.

9. Бохан Н.А., Аболонин А.Ф., Мандель А.И., Назарова И.Я., Стоянова И.Я. Агрессия и суицидальное поведение подростков в различных условиях социализации. Суицидология. 2018; 2 (31): 50-60.

10. Меринов А.В., Байкова М.А., Алексеева А.Ю. Семьи мужчин, страдающих алкогольной зависимостью: взгляд с позиции суицидологии. Суицидология. 2018; 2 (31): 92-99.

11. Hong H.-S., Park J.-E., Park W.-J. Predictors of hospitalization for alcohol use disorder in Korean men. J. Korean Acad. Nurs. 2014; 5 (44): 52-62. doi: 10.4040/jkan.2014.44.5.552

12. Любов Е.Б., Зотов П.Б. Диагностика суицидального поведения и оценка степени суицидального риска. Сообщение II. Суицидология. 2018; 2 (31): 16-30.

13. Меринов А.В., Байкова М.А., Зотова О.П. Трагическая смерть родственников как активный сценарный конструкт и его значение для суицидологической практики. Суицидология. 2017; 3 (28): 78-84.

14. Штайнер К. Сценарии жизни людей. СПб.: Питер, 2018: 416.

15. Шустов Д.И., Тучина О.Д. Психотерапия алкогольной зависимости: руководство для врачей. СПб.: СпецЛит, 2016: 415.

Поступила в редакцию 16.05.2018 Утверждена к печати 6.11.2018 
Меринов Алексей Владимирович, доктор медицинских наук, профессор кафедры психиатрии, доцент.

Байкова Мария Александровна, аспирант кафедры психиатрии.

Меринов Алексей Владимирович, merinovalex@gmail.com

Байкова Мария Александровна, baqkovamari@gmail.com

УДК 616.89-008.441.44:616.053.7:616.89.008.444.9:343.225-3-055.52

For citation: Merinov A.V., Baykova M.A. Influence of upbringing in the family with a parent affected by alcoholic dependence, on autoaggressive trajectory of the offspring. Siberian Herald of Psychiatry and Addiction Psychiatry. 2018; 4 (101): 87-92 https://doi.org/10.26617/1810-3111-2018-4(101)-87-92

\section{Influence of upbringing in the family with a parent affected by alcoholic depend- ence, on autoaggressive trajectory of the offspring}

\section{Merinov A.V., Baykova M.A.}

Ryazan State Medical University named after academician I.P. Pavlov

Vysokovoltnaya Street 9, 390010, Ryazan, Russian Federation

\section{ABSTRACT}

Introduction. The conundrum of adult children of alcoholics began to be raised by various psychiatric and drug treatment services about 10 years ago. And despite the distinct trend towards a decrease in alcohol dependence, the percent of people brought up in "alcoholic" families remains high. It is known that upbringing in such a family entails a whole layer of various kinds of psychological and social problems that sometimes turn out to be hidden from public eye. The aim of the work was to investigate the autoaggressive characteristics of girls and young men who grew up in the so-called "alcoholic" families. Materials and Research methods. The study involved 90 unmarried girls and 100 unmarried boys, brought up in families where at least one of the parents suffered from alcohol dependence. The control group consisted of 200 girls and 180 boys who did not have a parent suffering from alcohol use disorder. Statistical processing was carried out using parametric and nonparametric methods of mathematical statistics. Results of the study. In the study group, a significantly greater number of patterns of classical and non-classical suicidal behavior were found. In $12 \%$ of cases, boys from the studied groups had a suicide attempt in the history, while in the control group this percent was 0 . Girls from the studied group almost 5 times more likely than the respondents of the control group tried to commit suicide. Children brought up in families where the parent had an alcohol addiction constituted a special group with an increased risk of suicidal activity. Conclusion. Our data expanded the existing ideas about the negative impact of upbringing in an "alcoholic" family, convincingly demonstrated the fact that parental alcohol dependence is an important pro-suicidal phenomenon, and also demonstrated the need to create in the system of doctors of crisis and preventive services of understanding of definition Adult Children of Alcoholics.

\section{Keywords: adult children of alcoholics (ACOA), autoaggressive behavior, suicidology, alcoholism, alcohol use disorder.}

\section{REFERENCES}

1. Moskalenko V.D. Narkologicheskie, psihopatologicheskie narushenija, psihologicheskie problemy v populjacii vzroslyh synovej i docherej bol'nyh zavisimostjami [Narcological, psychopathological disorders, psychological problems in the population of adult sons and daughters of painful addicts]. Sibirskij vestnik psihiatrii $i$ narkologii - Siberian Herald of Psychiatry and Addiction Psychiatry. 2006; 3: 55-61 (in Russian).

2. Balsa A.I., Homer J.F., French M.T. The health effects of parental problem drinking on adult children. J. Ment. Health Policy Econ. 2009; 2 (12): 55-66.

3. Hall C.W., Webster R.E. Traumatic symptomatology characteristics of adult children of alcoholics. J. Drug Educ. 2002; 3 (32): 195-211.

4. Giuta C.T., Compas B.E. Adult daughters of alcoholics: are they unique? J. Stud. Alcohol. 1994; 5 (55): 600-606.

5. Jordan S. The promotion of resilience and protective factors in children of alcoholics and drug addicts. Bundesgesundheitsblatt Gesundheitsforschung Gesundheitsschutz. 2010; 4 (53): 340346 .

6. Woititz J.G. Guidelines for support groups; adult children of alcoholics and others who identify including guide to step 4 inventory. Health Communication. Inc. Pompano Beach, Florida, 1986: 37.

7. Van Den Berg N., Hennigan K., Hennigan D. Children of parents in drug/alcohol programs: are they underserved? Alcohol Treat. Quart.1989; 3 (4):1-25.

8. Shustov D.I., Merinov A.V. Diagnostika autoagressivnogo povedenija pri alkogolizme metodom terapevticheskogo interv'ju: posobie dlja vrachej psihiatrov-narkologov i psihotera- pevtov [Diagnosis of aggressive behavior in alcoholism by therapeutic interview: a manual for psychiatrists, psychotherapists and drug treatment]. Moscow: The Ministry of Health of the Russian Federation, 2000: 20 (in Russian).

9. Bokhan N.A., Abolonin A.F., Mandel' A.I., Nazarova I.YA., Stoyanova I.A. Agressiya i suicidal'noe povedenie podrostkov v razlichnyh usloviyah socializacii [Aggression and suicidal behavior of adolescents in various conditions of socialization]. Suicidologiya - Suicidology. 2018; 2 (31): 50-60 (in Russian).

10. Merinov A.V., Baykova M.A., Alekseeva A.Yu. Sem'i muzhchin, stradayushchih alkogol'noy zavisimost'yu: vzglyad s pozicii suicidologii [Families of men suffering from alcohol addiction: a view from the suicidology perspective]. Suicidologiya - Suicidology. 2018; 2 (31): 92-99 (in Russian).

11. Hong H.-S., Park J.-E., Park W.-J. Predictors of hospitalization for alcohol use disorder in Korean men. J. Korean Acad. Nurs. 2014; 5 (44): 52-62. doi: 10.4040/jkan.2014.44.5.552

12. Lyubov E.B., Zotov P.B. Diagnostika suicidal'nogo povedeniya i ocenka stepeni suicidal'nogo riska. Soobshchenie II. [Diagnostics of suicidal behavior and suicide risk evaluation. Report II]. Suicidologiya - Suicidology. 2018; 2 (31): 16-30 (in Russian).

13. Merinov A.V., Baykova M.A., Zotova O.P. Tragicheskaya smert' rodstvennikov kak aktivnyy scenarnyy konstrukt i ego znachenie dlya suicidologicheskoy praktiki [Tragic death of relatives as active precept's component and its importance for a suicide practice]. Suicidologiya - Suicidology. 2017; 3 (28): 78-84 (in Russian).

14. Shtayner K. Scenarii zhizni lyudey [Transactional Analysis of Life Scripts]. Saint-Petersburg: Piter, 2018: 416 (in Russian). 
15. Shustov D.I., Tuchina O.D. Psihoterapiya alkogol'noy zavisimosti: rukovodstvo dlya vrachey [Psychotherapy of alcohol addiction: a guide for doctors]. Saint-Petersburg: SpecLit, 2016:

Received May 16.2018 415 (in Russian).

Merinov Alexey V., MD, Professor of Psychiatry Department, associate professor, Ryazan State Medical University named after academician I.P. Pavlov, Ryazan, Russian Federation.

Baykova Maria A., post-graduate student of Psychiatry Department, associate professor, Ryazan State Medical University named after academician I.P. Pavlov, Ryazan, Russian Federation.

$\triangle$ Merinov Alexey V., merinovalex@gmail.com

$\triangle$ Baykova Maria A., baqkovamari@gmail.com 